EMERGENCY CASEBOOK

\title{
Traumatic dislocation of the testis: a rare sequel of perineal injury
}

\section{S M Blake, D M Bowley}

b esticular dislocation is a rare injury caused by a direct blow to the perineum. A high index of suspicion should be maintained, as delay in diagnosis is associated with loss of spermatogenic function of the testis and an increased rate of orchidectomy. ${ }^{12}$

\section{CASE REPORT}

A 21 year old motorcyclist collided with the back of a slow moving vehicle at about $30 \mathrm{mph}$. In addition to a fracture of the left superior pubic ramus, he was noted to have a tender lump in the right lower abdomen and an empty right hemiscrotum (fig 1). The diagnosis of traumatic testicular dislocation was confirmed by ultrasound (fig 2). Closed reduction was unsuccessful and exploration and orchidopexy was undertaken.

\section{DISCUSSION}

The most common mechanism of testicular dislocation is in motorcycle accidents when the rider is propelled forwards striking his perineum on the fuel tank.

On reaching the external ring the testis may be pushed into the inguinal canal and proceed as far as the retroperitoneum. More commonly, the testis comes to lie in the superficial inguinal pouch.

An ultrasound scan can help to localise the testis and will demonstrate capsular or parenchymal damage. ${ }^{3}$ If the testis is intact and normally perfused closed reduction under sedation may be attempted. If this fails, then exploration and

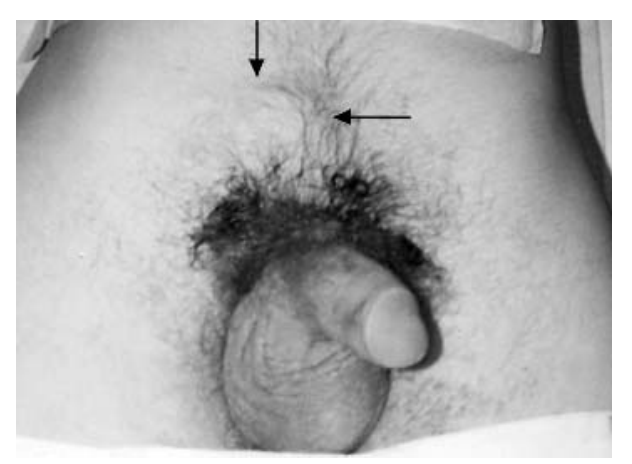

Figure 1 Displaced testis (arrows) and empty right hemiscrotum.

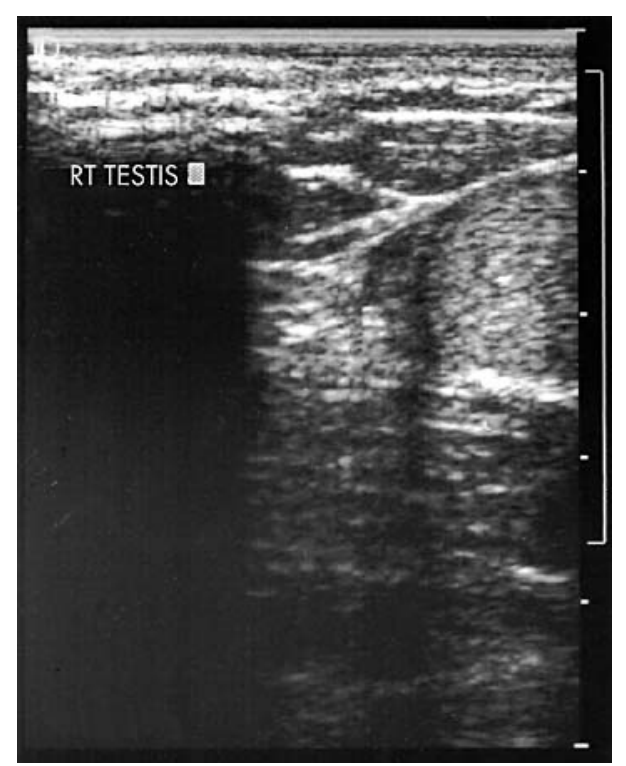

Figure 2 Ultrasound confirmation of a dislocated testis.

orchidopexy is indicated. If there is any doubt concerning the viability of the testis then prompt exploration should be undertaken.

\section{Authors' affiliations}

S M Blake, D M Bowley, North Devon District Hospital, Trauma and Orthopaedic Surgery, Barnstaple, UK

Correspondence to: Mr S M Blake, Department of Orthopaedic Surgery, Level 11, Derriford Hospital, Plymouth PL6 8DH, UK;

stephenblake_uk@yahoo.co.uk

Accepted for publication 18 December 2002

\section{REFERENCES}

1 Del Villar R, Ireland GW, Cass AS. Early exploration following trauma to the testicle. J Trauma 1973;13:600-2.

2 Hayami S, Ishigooka M, Suzuki Y, et al. Pathological changes of traumatic, dislocated testis. Urol Int 1996:56:129-32.

3 Morgan A. Traumatic luxation of the testis: addition of two cases with a changing aetiology. Br J Surg 1965;52:669-70. 